\title{
Các yếu tố ảnh hưởng đến quyết định thuê ngoài dịch vụ thực hiện thủ tục đăng ký doanh nghiệp của các doanh nghiệp tại Thành phố Cần Tho
}

\section{Factors affecting the outsourcing services of business registration in Can Tho City}

\author{
Nguyễn Thị Mỹ Loan ${ }^{1}$, Quan Minh Nhựt ${ }^{2}$, Phạm Thế Thông ${ }^{2 *}$ \\ ${ }^{1}$ Công an Thành phố Cần Thơ, Việt Nam \\ ${ }^{2}$ Trường Đại học Cần Thơ, Việt Nam \\ *Tác giả liên hệ, Email: plthong@ctu.edu.vn
}

\begin{tabular}{|c|c|}
\hline THÔNG TIN & TÓM TẮT \\
\hline $\begin{array}{l}\text { DOI:10.46223/HCMCOUJS. } \\
\text { econ.vi.14.1.501.2019 }\end{array}$ & $\begin{array}{l}\text { Mục tiêu của nghiên cứu này nhằm xác định các yếu tố } \\
\text { ảnh hưởng đến quyết định thuê ngoài dịch vụ thực hiện thủ } \\
\text { tục đăng ký doanh nghiệp của các doanh nghiệp tại thành phố } \\
\text { Cần Thơ. Với số liệu từ mẫu điều tra } 171 \text { doanh nghiệp, kêt }\end{array}$ \\
\hline Ngày nhận: 30/10/2018 & \\
\hline Ngày nhận lại: 10/12/2018 & doanh nghiệp của các doanh nghiệp bao gồm: phí dịch vụ, \\
\hline Duyệt đăng: 14/01/2019 & $\begin{array}{l}\text { thời gian, qui mô doanh nghiệp, năm thành lập và các loại } \\
\text { giấy tờ. Dựa trên kết quả nghiên cứu, một số khuyến nghị đối } \\
\text { với doanh nghiệp và một số hàm ý chính sách đối với Sở Kế } \\
\text { hoach và Đầu tư thành phố Cần Thơ đã được đề xuất nhằm }\end{array}$ \\
\hline Tù khóa: & \\
\hline $\begin{array}{l}\text { đăng ký doanh nghiệp, dịch vụ } \\
\text { thuê ngoài, mô hình hồi quy, } \\
\text { Thành phố Cần Thơ }\end{array}$ & $\begin{array}{l}\text { đơn giản, nhanh chóng, minh bạch để tạo điều kiện cho doanh } \\
\text { nghiệp tự thực hiện thay vì thuê ngoài dịch vụ. }\end{array}$ \\
\hline
\end{tabular}

Thành phô Cần Thơ

Keywords:

business registration, Can Tho City, logit model, outsourcing

\section{ABSTRACT}

The study investigated the factors that affected the outsourcing decisions of business registration services in Can Tho City. Using data from a sample of 171 enterprises, the estimation results from a logit model showed that there were five factors affecting the outsourcing decisions of business registration services which included fee, time, company size, year of establishment and the number of required documents. Based on these results, some recommendations were proposed for enterprises as well as for the Department of Planning and investment of Can Tho City in order to facilitate the enterprises to fulfil the business registration procedures. 


\section{1. Đặt vấn đề}

Thuê ngoài ngày càng trở nên phổ biến trong nhiều lĩnh vực và đây là một trong những quyết định chiến lược thu hút sự quan tâm lớn từ các chuyên gia và các học giả trên thế giới (Espino-Rodríguez \& Padrón-Robaina, 2006). Thuê ngoài khá phổ biến trong lĩnh vực sản xuất thương mại chẳng hạn như thuê dịch vụ kế toán, công nghệ thông tin, ... Thuê ngoài là việc doanh nghiệp đi thuê một nhà cung ứng dịch vụ bên ngoài để họ thực hiện một phần hay toàn bộ các phần công việc tại doanh nghiệp thay vì bản thân doanh nghiệp phải thực hiện tất cả những phần việc ấy (Yang, Kim, Nam, \& Min, 2007).

Các lĩnh vực thuê ngoài phổ biến hiện nay được doanh nghiệp lựa chọn như là: thuê ngoài công nghệ thông tin (Djavanshir, 2005; Earl, 1996), thuê ngoài nhân sự (Çiçek \& Özer, 2011; Gilley \& Rasheed, 2000), thuê ngoài dịch vụ kế toán (Cullinan \& Zheng, 2015), ... Đây là những dịch vụ mà sau khi được thành lập và đi vào hoạt động, doanh nghiệp sẽ phải cân nhắc tình hình của doanh nghiệp để đi đến quyết định có nên lựa chọn dịch vụ thuê ngoài hay không. Việc thuê ngoài trong lĩnh vực khác chẳng hạn như lĩnh vực hành chính công cũng có xảy ra (Hood, 1997). Đó là việc khi doanh nghiệp thuê một tổ chức, cá nhân thực hiện và tạo ra một sản phẩm mà sản phẩm này được cung cấp từ cơ quan nhà nước. Cụ thể, theo Luật doanh nghiệp (Quốc Hội, 2014), một doanh nghiệp ở Việt Nam trước khi được thành lập phải đăng ký các loại giấy phép tùy theo lĩnh vực mình hoạt động, trong đó không thể thiếu giấy chứng nhận đăng ký doanh nghiệp.

Do các văn bản Luật không quy định phải chính bản thân doanh nghiệp là người trực tiếp đi thực hiện thủ tục đăng ký doanh nghiệp nên đã có rất nhiều doanh nghiệp thuê công ty tư vấn dịch vụ để hoàn thành thủ tục vì một số lý do: thủ tục còn rườm rà, tốn kém thời gian,... nên nhiều tổ chức, cá nhân buộc phải tìm đến các công ty tư vấn để tìm kiếm sự giúp đỡ.

Trong lĩnh vực sản xuất thương mại, lợi ích từ việc thuê ngoài sẽ giúp doanh nghiệp cắt giảm chi phí kinh doanh (Çiçek \& Özer, 2011; Gilley \& Rasheed, 2000), tăng lợi nhuận (Akuamoah-Boateng et al., 2012; Hamzah, Aman, Maelah, Auzair, \& Amiruddin, 2010), giảm bớt tính cồng kềnh của bộ máy (Alfred, Sumari, \& Mori, 2013; Assaf, Hassanain, Al-Hammad, \& Al-Nehmi, 2011), nâng cao năng lực cạnh tranh (Alfred et al., 2013; Çiçek \& Özer, 2011). Tuy nhiên, bên cạnh những lợi ích từ việc thuê ngoài mang lại thì các doanh nghiệp cũng gặp không ít những rủi ro như: phụ thuộc nhà cung cấp (Ketler \& Walstrom, 1993; Kremic, Tukel, \& Rom, 2006), mất khả năng kiểm soát thuê (Ketler \& Walstrom, 1993; Quinn, 2000), gián đoạn quá trình thực hiện công việc (Belcourt, 2006), nguy cơ bị lộ bí mật, thông tin doanh nghiệp (Ketler \& Walstrom, 1993). Ngoài ra, quyết định của các doanh nghiệp khi sử dụng dịch vụ thuê ngoài không chỉ bị tác động từ những lợi ích mà nó mang lại hay những rủi ro gặp phải mà còn phụ thuộc vào nhiều nhân tố khác như định hướng chiến lược của doanh nghiệp (Assaf et al., 2011), đặc điểm của doanh nghiệp (Ketler \& Walstrom, 1993; Kremic et al., 2006), hay hình ảnh nhà cung cấp dịch vụ (Ketler \& Walstrom, 1993).

Tuy nhiên, trong lĩnh vực hành chính công, các yếu tố nào sẽ ảnh hưởng đến quyết định của doanh nghiệp tự thực hiện hay thuê dịch vụ, đó vẫn là câu hỏi cho các nhà nghiên cứu? Hiện nay, chưa có nghiên cứu nào tại Việt Nam về các yếu tố tác động đến quyết định thuê ngoài dịch vụ thực hiện thủ tục đăng ký doanh nghiệp của các doanh nghiệp. Do vậy, việc nghiên cứu các yếu tố ảnh hưởng đến quyết định thuê ngoài dịch vụ thực hiện thủ tục đăng ký doanh nghiệp của các doanh nghiệp trên địa bàn Thành phố Cần Thơ là thật sự cần thiết. Kết quả nghiên cứu là cơ sở để các sở, ban, ngành đặc biệt là Sở Kế hoạch và Đầu tư và Cục thuế 
của các tỉnh, thành phố tham khảo và vận dụng trong việc quản lý và nâng cao chất lượng dịch vụ đăng ký doanh nghiệp nhằm phục vụ nhu cầu của các doanh nghiệp ngày một tốt hơn. Đây cũng là cơ sở nghiên cứu cho lĩnh vực hành chính công và bổ sung vào nguồn tài liệu nghiên cứu trong lĩnh vực này.

\section{Cơ sở lý thuyết và phương pháp nghiên cứu}

\subsection{Cơ sở lý thuyết và mô hình nghiên cúu}

Hầu hết các nghiên cứu liên quan đến thuê ngoài đều sử dụng lý thuyết chi phí giao dịch (TCE) để giải thích, trong đó, Coase (1937) là người đầu tiên đưa ra lý thuyết này. Theo lý thuyết TCE thì doanh nghiệp muốn mua một sản phẩm hoặc dịch vụ thì doanh nghiệp phải chịu các khoản chi phí bao gồm: tìm kiếm giá cả, tìm kiếm nhà cung cấp, đàm phán, làm hợp đồng và chúng được gọi là chi phí giao dịch. Tuy nhiên, người có công phát triển khái niệm chi phí giao dịch là O’Brien (1976) và ông đã giải thích được lý do tại sao lý thuyết TCE được các nghiên cứu liên quan đến vấn đề thuê ngoài sử dụng rộng rãi, đó là bởi vì nó cung cấp được công cụ quan trọng trong việc hỗ trợ các doanh nghiệp đưa ra quyết định sử dụng dịch vụ thuê ngoài.

Có rất nhiều nghiên cứu đã vận dụng thành công lý thuyết chi phí giao dịch của Coase (1937) khi xây dựng mô hình các yếu tố quyết định sử dụng dịch vụ thuê ngoài của các doanh nghiệp. Chẳng hạn như, nghiên cứu của Ketler và Walstrom (1993) tại Hoa Kỳ cho thấy 6 yếu tố: (i) chất lượng nhân sự trong tổ chức; (ii) lợi ích về kinh tế đạt được khi thuê ngoài; (iii) khả năng kiểm soát các hoạt động của nhà cung ứng dịch vụ; (iv) vấn đề bảo mật thông tin và dữ liệu trong doanh nghiệp; (v) đặc điểm của công việc trong doanh nghiệp và (vi) tiêu chuẩn nhà cung ứng dịch vụ ảnh hưởng đến việc thuê ngoài. Hay kết quả nghiên cứu của Kremic và cộng sự (2006), vận dụng lý thuyết chi phí giao dịch kết hợp với lý thuyết năng lực cốt lõi nhằm xây dựng mô hình hỗ trợ các doanh nghiệp trong việc đưa ra quyết định sử dụng dịch vụ thuê ngoài, khẳng định rằng quyết định của doanh nghiệp không chỉ phụ thuộc vào yếu tố lợi ích và yếu tố rủi ro mà còn phụ thuộc vào yếu tố định hướng chiến lược và yếu tố đặc điểm chức năng của doanh nghiệp. Đến năm 1996, Argyres (1996) đã nhấn mạnh trong nghiên cứu của mình rằng ngoài các yếu tố như khả năng của doanh nghiệp, khả năng cung cấp dịch vụ của nhà cung cấp thì yếu tố kiến thức của người quản lý doanh nghiệp về vấn đề cần thuê dịch vụ là rất cần thiết. Tuy nhiên, hạn chế của các nghiên cứu này là do chỉ quan tâm đến các yếu tố nội bộ của doanh nghiệp mà chưa quan tâm đến ảnh hưởng của các yếu tố bên ngoài.

Ngoài ra, hạn chế của lý thuyết TCE là chỉ kiểm định mối quan hệ giữa bên thuê dịch vụ và bên cung cấp dịch vụ nhưng xét trên góc độ giao dịch kinh tế thì mối quan hệ giao dịch không chỉ ảnh hưởng giữa bên thuê dịch vụ và bên cung cấp dịch vụ mà mối quan hệ kinh tế còn chịu tác động bởi những mối quan hệ khác trong đó có mối quan hệ xã hội của người quản lý doanh nghiệp, đây cũng là điểm khác biệt so với các nghiên cứu trước đây và cũng là điểm đặc biệt đối với dịch vụ được cung cấp từ các cơ quan hành chính nhà nước. Giải thích cho vấn đề này những năm 1990 lý thuyết mạng lưới xã hội được nhiều nghiên cứu thực nghiệm sử dụng trong các bối cảnh và lĩnh vực nghiên cứu đa dạng với các mô hình lý thuyết mô tả những người như các nút của một đồ thị và các mối quan hệ của họ như các cạnh của biểu đồ (Wasserman \& Faust, 1994; Watts \& Strogatz, 1998).

Các nghiên cứu của Bourdieu (1986) và Coleman (1988) là nguồn gốc của lý thuyết mạng lưới xã hội. Mạng lưới xã hội là một trong hai thành phần của lý thuyết vốn xã hội, được dùng để chỉ phức thể các mối quan hệ xã hội do con người xây dựng, duy trì và phát triển trong 
cuộc sống thực của họ với tư cách là thành viên của xã hội. Từ đây, mạng lưới xã hội của người quản lý doanh nghiệp sẽ giữ vai trò quan trọng khi đưa ra quyết định có nên lựa chọn thuê ngoài hay không. Bởi vì lợi ích của việc có mối quan hệ xã hội là có được những thông tin quan trọng từ những người có hiểu biết, tiếp cận được những người có kiến thức về vấn đề họ cần (Blau, 1977; Burt \& Celotto, 1992; Granovetter, 1983), qua đó đã giải thích được lý do các nhà quản lý doanh nghiệp càng có nhiều mối quan hệ xã hội càng có xu hướng ít thuê ngoài.

Như vậy, từ cơ sở lý thuyết và các nghiên cứu thực nghiệm ta thấy có rất nhiều các yếu tố ảnh hưởng đến quyết định thuê ngoài của doanh nghiệp như: lợi ích, rủi ro, định hướng chiến lược, đặc điểm chức năng của doanh nghiệp, kiến thức của người quản lý doanh nghiệp,... Tuy nhiên, trong nghiên cứu này, tác giả có điều chỉnh và bổ sung thêm các biến thông qua việc khảo sát sơ bộ là các doanh nghiệp có thuê công ty tư vấn thực hiện thủ tục đăng ký doanh nghiệp cho phù hợp với bối cảnh, đặc thù của lĩnh vực hành chính công như mối quan hệ xã hội của người quản lý doanh nghiệp. Từ đó, tác giả đề xuất 4 nhóm yếu tố ảnh hưởng quyết định thuê ngoài dịch vụ thực hiện thủ tục đăng ký doanh nghiệp của các doanh nghiệp đó là: lợi ích, đặc điểm doanh nghiệp, kiến thức của người quản lý doanh nghiệp và mối quan hệ xã hội của người quản lý doanh nghiệp.

\subsubsection{Yếu tố lợi ích}

Khi xem xét đến lợi ích có được khi quyết định thuê một cá nhân/tổ chức thực hiện các công việc của doanh nghiệp, kết quả của hầu hết các nghiên cứu trước đây đều khẳng định rằng lợi ích khi sử dụng dịch vụ thuê ngoài là một yếu tố quan trọng ảnh hưởng đến xu hướng sử dụng dịch vụ thuê ngoài của các doanh nghiệp (Assaf et al., 2011; Bhagat, Byramjee, \& Taiani, 2010; Hafeez \& Andersen, 2014). Thật vậy, lợi ích có được từ việc thuê ngoài trong lĩnh vực sản xuất thương mại thể hiện ở việc doanh nghiệp sẽ tập trung thực hiện các chức năng cốt lõi, tăng được tính linh hoạt cho doanh nghiệp (Assaf et al., 2011; Nyaboke, Amemba, \& Osoro, 2013), tiếp cận đội ngũ nhân viên chuyên môn cao (Sani, Dezdar, \& Sulaiman, 2013), ...

Trên cơ sở đó, ta thấy tuy xuất phát từ các động cơ thuê ngoài khác nhau nhưng phần lớn các nghiên cứu đều xác định lợi ích có được từ việc thuê ngoài gồm các yếu tố thể hiện mong muốn tiết kiệm chi phí của các doanh nghiệp. Tuy nhiên, trong lĩnh vực hành chính công, cụ thể là lĩnh vực đăng ký doanh nghiệp thì lợi ích thể hiện ở việc tiết kiệm chi phí cơ hội mà doanh nghiệp phải bỏ ra khi sử dụng dịch vụ thuê ngoài. Chi phí cơ hội này bao gồm phí dịch vụ mà doanh nghiệp phải bỏ ra, thời gian doanh nghiệp tiết kiệm được nếu thuê cá nhân/tổ chức thực hiện, cụ thể là thời gian chuẩn bị hồ sơ, thời gian chờ đợi nộp hồ sơ và nhận kết quả, ... và số lần đi lại của doanh nghiệp khi thực hiện thủ tục đăng ký doanh nghiệp. Như vậy, lợi ích từ việc thuê ngoài có tác động tích cực đến quyết định thuê của doanh nghiệp.

\subsubsection{Yếu tố đặc điểm doanh nghiệp}

Yếu tố đặc điểm của doanh nghiệp liên quan đến các vấn đề nội bộ của doanh nghiệp và đây cũng được xem là yếu tố có ảnh hưởng đến quyết định có nên thuê dịch vụ bên ngoài thực hiện các công việc bên trong của doanh nghiệp (Hafeez \& Andersen, 2014; Ketler \& Walstrom, 1993; Kremic et al., 2006). Trong lĩnh vực sản xuất thương mại, yếu tố đặc điểm doanh nghiệp thể hiện ở bản chất của các công việc cụ thể là tính chất công việc, mức độ bảo mật thông tin trong doanh nghiệp (Assaf et al., 2011; Ketler \& Walstrom, 1993; Kremic et al., 2006), quy mô hoạt động của doanh nghiệp (Hafeez \& Andersen, 2014; Kamyabi \& Devi, 2011),... 
Xét ở lĩnh vực khác cụ thể là lĩnh vực đăng ký doanh nghiệp, ta thấy đặc điểm doanh nghiệp đầu tiên thể hiện ở việc trụ sở của doanh nghiệp ở gần hay quá xa với nơi đăng ký thủ tục. Có một số ý kiến của các chuyên gia cho rằng khoảng cách địa lý là vấn đề đáng lo ngại khi các doanh nghiệp phải tự thực hiện thủ tục trong khi trụ sở của họ quá xa so với nơi đăng ký. Việc đi lại nhiều lần nếu hồ sơ chưa hoàn chỉnh, chi phí bằng tiền và thời gian phải bỏ ra khi tự thực hiện là điều doanh nghiệp phải cân nhắc có nên quyết định thuê dịch vụ bên ngoài thực hiện hay không? Bên cạnh đó, yếu tố quy mô hoạt động của doanh nghiệp thể hiện qua số lao động, vốn điều lệ của doanh nghiệp cũng ảnh hưởng đáng kể đến quyết định thuê ngoài của doanh nghiệp. Ngoài ra, qua việc phỏng vấn chuyên gia là các doanh nghiệp đã từng thuê dịch vụ, họ cho rằng xu hướng sử dụng dịch vụ thuê ngoài cũng phụ thuộc vào năm doanh nghiệp thành lập hoặc thay đổi nội dung đăng ký kinh doanh. Vì trước khi Luật doanh nghiệp năm 2014 ra đời và bắt đầu có hiệu lực từ năm 2015 thì thời gian mà doanh nghiệp phải bỏ ra để có được Giấy chứng nhận đăng ký doanh nghiệp là 05 ngày làm việc (Chính phủ, 2010), do đó sau khi rút ngắn được thời gian còn 3 ngày làm việc đã tạo điều kiện thuận lợi cho doanh nghiệp trong quá trình chuẩn bị đi vào hoạt động. Qua đó, ta có thể khẳng định rằng có sự tác động của yếu tố đặc điểm doanh nghiệp đến quyết định thuê ngoài dịch vụ của doanh nghiệp.

\subsubsection{Yếu tố kiến thức của người quản lý doanh nghiệp}

Theo Nordhaug (1993) kiến thức là "những thông tin chuyên biệt về một chủ đề hoặc một lĩnh vực nào đó”. Nghiên cứu của Cooper, Gimeno-Gascon, và Woo (1994) cho rằng người quản lý doanh nghiệp có trình độ chuyên môn cao sẽ có năng lực để giải quyết các vấn đề phức tạp tốt hơn. Điều đó cũng được chứng minh trong nghiên cứu của Argyres (1996). Tuy nhiên, đặc thù trong nghiên cứu này là ở lĩnh vực hành chính công nên đòi hỏi người quản lý doanh nghiệp cũng cần có những kiến thức cơ bản về các thủ tục hành chính cũng như chuyên ngành học có liên quan đến việc hiểu biết những văn bản pháp luật và quy trình thực hiện thủ tục là rất cần thiết. Do đó, kiến thức của người quản lý doanh nghiệp là một yếu tố tác động tích cực đến quyết định thuê của doanh nghiệp.

\subsubsection{Yếu tố mối quan hệ xã hội của ngườ quản lý doanh nghiệp}

Theo lập luận của Bourdieu (1986), vốn xã hội là toàn bộ nguồn lực (thực tế hoặc tiềm ẩn) xuất phát từ mạng lưới quen biết trực tiếp hay gián tiếp. Những cá nhân, gia đình hay tập thể nào càng có nhiều các quan hệ thì nắm giữ càng nhiều ưu thế. Ngược lại, Coleman (1988) khẳng định vốn xã hội là các khía cạnh của cấu trúc xã hội mà những khía cạnh này tạo thuận lợi cho hành động của các cá nhân. Qua đó, người ta thiết lập và duy trì những mối quan hệ để tìm kiếm lợi ích. Tuy có nhiều cách giải thích khác nhau nhưng qua đó, ta có thể thấy mối quan hệ xã hội trong nghiên cứu này là một mạng lưới quan hệ giữa cá nhân người quản lý doanh nghiệp với tổ chức/cá nhân cung cấp dịch vụ thuê ngoài để có được sự tư vấn hoặc điều kiện thuận lợi khi tìm hiểu. Cũng như việc tự bản thân doanh nghiệp trực tiếp đến liên hệ thực hiện thủ tục thì việc có được sự quen biết với những cán bộ làm việc trực tiếp tại các cơ quan hành chính nhà nước thì họ sẽ được hướng dẫn hồ sơ rõ ràng, chi tiết hoặc được ưu tiên không mất thời gian chờ nộp hồ sơ và nhận kết quả. Từ cơ sở trên, ta thấy yếu tố mối quan hệ xã hội của người quản lý doanh nghiệp có tác động tích cực đến quyết định thuê ngoài của doanh nghiệp.

Dựa trên các cơ sở lý thuyết, nghiên cứu thực nghiệm và thực tiễn, tác giả xây dựng mô hình nghiên cứu, được trình bày trong Hình 1 . 


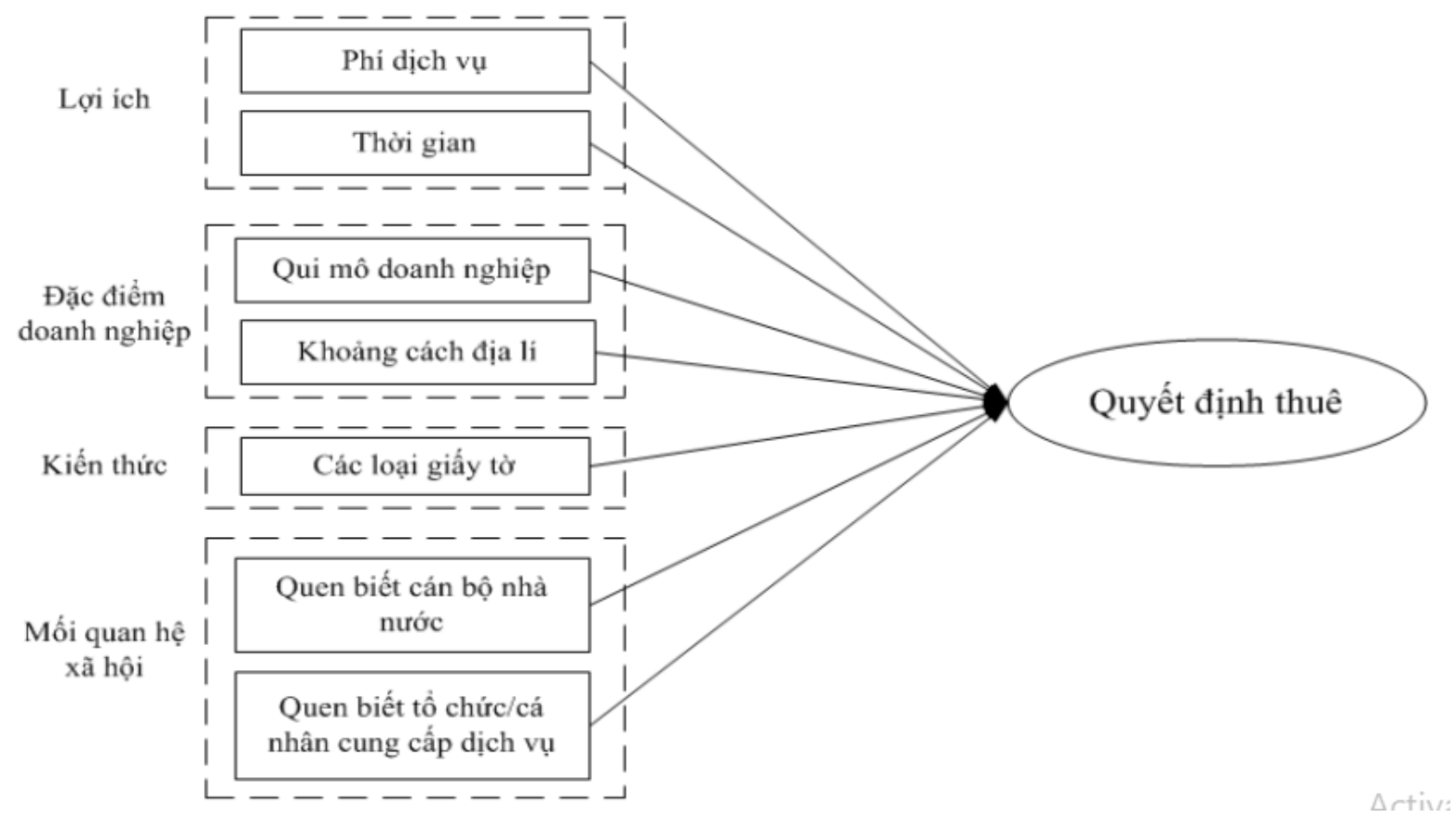

Hình 1. Mô hình nghiên cứu đề xuất các nhân tố ảnh hưởng quyết định thuê dịch vụ thực hiện thủ tục đăng ký doanh nghiệp cho các doanh nghiệp trên địa bàn TPCT

\subsection{Phương pháp nghiên cúu}

\subsubsection{Phuoong pháp thu thập số liệu sơ cấp}

Trên cơ sở lý thuyết và lược khảo tài liệu, tác giả tổng hợp các yếu tố ảnh hưởng đến quyết định thuê dịch vụ thực hiện thủ tục đăng ký doanh nghiệp. Sau đó, tác giả thực hiện nghiên cứu định tính bằng việc trao đổi sâu với các chuyên gia là các nhà quản lý doanh nghiệp có thuê và không thuê dịch vụ để thiết kế bảng câu hỏi. Dựa trên bảng câu hỏi, tác giả tiến hành phỏng vấn các nhà quản lý doanh nghiệp tại các doanh nghiệp đang hoạt động trên địa bàn Thành phố Cần Thơ. Theo đó, đối tượng phỏng vấn là những người có quyền đưa ra quyết định thuê hay không thuê ngoài dịch vụ thực hiện thủ tục đăng ký doanh nghiệp cho các doanh nghiệp.

Các doanh nghiệp được chọn mẫu theo phương pháp ngẫu nhiên đơn giản. Từ danh sách tên và địa chỉ các doanh nghiệp trên địa bàn Thành phố Cần Thơ được cung cấp bởi Sở Kế hoạch và Đầu tư và Hiệp hội doanh nghiệp IBN, tác giả chọn ra ngẫu nhiên 250 doanh nghiệp và liên hệ người có quyền quyết định trong doanh nghiệp để thực hiện phỏng vấn trực tiếp dựa trên bản câu hỏi soạn sẵn. Trong quá trình tiếp cận các doanh nghiệp, nhóm nghiên cứu thu thập được thông tin từ 171 doanh nghiệp do có một số nhà quản lý từ chối tiếp xúc.

Theo Tabachnick và Fidell (1996), đối với phân tích hồi quy đa biến, cỡ mẫu tối thiểu cần đạt được theo công thức $\mathrm{n}=50+8 \times \mathrm{m}$ ( $\mathrm{m}$ là số biến độc lập). Nghiên cứu này sử dụng 9 biến quan sát nên cần điều tra tối thiểu 122 đáp viên. Tuy nhiên, để phòng ngừa những phiếu phỏng vấn không hợp lệ và dựa trên điều kiện về thời gian và tài chính, tác giả chọn cỡ mẫu là 250 .

\subsubsection{Phương pháp phân tích số liệu}

Tác giả sử dụng mô hình hồi qui logit để phân tích các yếu tố có ảnh hưởng đến quyết 
định thuê ngoài dịch vụ thực hiện thủ tục đăng ký doanh nghiệp của các doanh nghiệp trên địa bàn Thành phố Cần Thơ. Mô hình ước lượng được viết dưới dạng sau:

$$
\operatorname{Pr}(Q Đ=1 \mid X)=F\left(\beta_{0}+\beta_{1} C P B T+\beta_{2} C P T G+\beta_{3} S L G T+\beta_{4} K C+\beta_{5} Q M+\right.
$$

$\left.\beta_{6} Q B C B N N+\beta_{7} Q B C C D V+\beta_{8} B G 2015+\beta_{9} C P B T . C P T G\right)$

Trong đó: biến phụ thuộc $\mathrm{Q} Đ$ biểu diễn quyết định của doanh nghiệp về thuê dịch vụ thực hiện thủ tục đăng ký doanh nghiệp, nhận hai giá trị là $0=$ Không thuê, $1=$ Thuê. Các biến độc lập được diễn giải trong Bảng 1 .

\section{Bảng 1}

Các biến số trong mô hình nghiên cứu thực nghiệm

\begin{tabular}{|c|c|c|c|}
\hline Tên biến & Ký hiệu biến & Mô tả biến & $\begin{array}{l}\text { Dấu kỳ } \\
\text { vọng của } \\
\text { hệ số }\end{array}$ \\
\hline $\begin{array}{l}\text { Biến phụ thuộc } \\
\text { QUYÊT ĐỊNH }\end{array}$ & $\mathrm{Q}$ & $\begin{array}{l}\text { Quyết định của } \mathrm{DN} \text { nhận hai giá trị là } \\
1=\text { Thuê, } 0=\text { Không thuê }\end{array}$ & \\
\hline \multicolumn{4}{|l|}{ Biến độc lập } \\
\hline Phí dịch vụ & CPBT & $\begin{array}{l}\text { Số tiền doanh nghiệp phải bỏ ra để } \\
\text { tự thực hiện hoặc thuê tổ chức/cá } \\
\text { nhân thực hiện thủ tục đăng ký } \\
\text { doanh nghiệp (triệu đồng) } \\
\text { Thời gian doanh nghiệp phải bỏ ra }\end{array}$ & + \\
\hline Thời gian & CPTG & $\begin{array}{l}\text { để tự thực hiện hoặc thuê tổ chức/cá } \\
\text { nhân thực hiện để có được Giấy } \\
\text { chứng nhận đăng ký doanh nghiệp } \\
\text { (ngày) }\end{array}$ & + \\
\hline Số loại giấy tờ & SLGT & $\begin{array}{l}\text { Tỷ lệ sô loại giây tờ doanh nghiệp } \\
\text { biết được trong tồng số loại giấy tờ } \\
\text { DN cần phải có khi thực hiện thủ tục } \\
\text { đăng ký (\%) } \\
\text { Khoảng cách đia lv́ từ tru sở của }\end{array}$ & - \\
\hline Khoảng cách địa lý & $\mathrm{KC}$ & $\begin{array}{l}\text { doanh nghiệp đến nơi đăng ký thủ } \\
\text { tum) }\end{array}$ & + \\
\hline Qui mô doanh nghiệp & QM & $\begin{array}{l}\text { Vồn điều lệ của } \mathrm{DN} \text { đang hoạt động } \\
\text { (tỷ đồng) } \\
\text { Người quản lý } \mathrm{DN} \text { có quen biết với }\end{array}$ & - \\
\hline $\begin{array}{l}\text { Quen biết cán bộ nhà } \\
\text { nước }\end{array}$ & QB CBNN & $\begin{array}{l}\text { CBNN (Có quen }=1 \text {; Không quen } \\
=0 \text { ) } \\
\text { Người quản lý DN có quen biết với }\end{array}$ & - \\
\hline $\begin{array}{l}\text { Quen biết tổ chức/cá } \\
\text { nhân CCDV }\end{array}$ & QB CCDV & $\begin{array}{l}\text { tổ chức/cá nhân CCDV (Có quen } \\
=1 ; \text { Không quen }=0 \text { ) } \\
\text { Người quản lý DN cân nhắc việc nếu }\end{array}$ & - \\
\hline $\begin{array}{l}\text { Tích số của chi phí } \\
\text { bằng tiền và chi phí } \\
\text { thời gian }\end{array}$ & СРВТ.CРТG & $\begin{array}{l}\text { mất nhiều tiền thì sẽ ít tốn thời gian } \\
\text { và ngược lại tốn ít tiền sẽ mất nhiều } \\
\text { thời gian đi lại }\end{array}$ & - \\
\hline $\begin{array}{l}\text { Biến kiểm soát } \\
\text { Doanh nghiệp đăng }\end{array}$ & BG2015 & $\begin{array}{l}\text { Năm } 2015 \text { là năm doanh nghiệp } \\
\text { thành lập hoặc thay dổi nội dung }\end{array}$ & - \\
\hline
\end{tabular}




\begin{tabular}{|c|c|c|c|}
\hline Tên biến & Ký hiệu biến & Mô tả biến & $\begin{array}{c}\text { Dấu kỳ } \\
\text { vọng của } \\
\text { hệ số }\end{array}$ \\
\hline ký sau năm 2015 & & $\begin{array}{l}\text { đăng ký kinh doanh (Trước năm } \\
2015=0 ; \text { Sau năm 2015=1) }\end{array}$ & \\
\hline
\end{tabular}

Nguồn: Kết quả phân tích dữ liệu của nhóm nghiên cứu

\section{Kết quả nghiên cứu và thảo luận}

\subsection{Thông tin chung về mẫu nghiên cứu}

Trong 171 doanh nghiệp được khảo sát, có 107 doanh nghiệp (chiếm tỷ trọng 62,57\%) có thuê dịch vụ bên ngoài và 64 doanh nghiệp (chiếm tỷ trọng 37,43\%) tự thực hiện được thủ tục đăng ký doanh nghiệp cho doanh nghiệp mình. Ngoài ra, nhân tố mối quan hệ xã hội của nhà quản lý doanh nghiệp cũng được cho là có ảnh hưởng đến quyết định thuê của doanh nghiệp. Điều đó được thể hiện ở việc có quen biết với cán bộ nhà nước và có quen biết với tổ chức/cá nhân cung cấp dịch vụ.

Theo số liệu trong Bảng 2, có 60 doanh nghiệp (chiếm tỷ trọng 35,09\%) cho rằng họ có quen biết với cán bộ nhà nước và 111 doanh nghiệp (chiếm tỷ trọng 64,91\%) không có sự quen biết với cán bộ nhà nước. Ngoài ra, xét về mối quan hệ quen biết của doanh nghiệp với tổ chức/cá nhân cung cấp dịch vụ, có 131 doanh nghiệp (chiếm tỷ trọng 76,61\%) cho rằng không cần phải có sự quen biết với tổ chức/cá nhân cung cấp dịch vụ và 40 doanh nghiệp (chiếm tỷ trọng $23,39 \%$ ) cho rằng cần có mối quan hệ quen biết với tổ chức/cá nhân cung cấp dịch vụ.

\section{Bảng 2}

Mô tả nghiên cứu

\begin{tabular}{|c|c|c|}
\hline Chỉ tiêu & Tần số & $\begin{array}{c}\text { Tỷ trọng } \\
(\%)\end{array}$ \\
\hline \multicolumn{3}{|l|}{ Quyết định của doanh nghiệp } \\
\hline Thuê & 107 & 62,57 \\
\hline Không thuê & 64 & 37,43 \\
\hline Tổng & 171 & 100 \\
\hline \multicolumn{3}{|l|}{ Trình độ học vấn của người quản lý doanh nghiệp } \\
\hline Trên trung cấp & 150 & 87,72 \\
\hline Dưới trung cấp & 21 & 12,28 \\
\hline Tổng & 171 & 100 \\
\hline \multicolumn{3}{|l|}{ Chuyên ngành học của người quản lý doanh nghiệp } \\
\hline Chuyên ngành học có liên quan đến Luật & 110 & 73,33 \\
\hline Chuyên ngành học không có liên quan đến Luật & 40 & 26,67 \\
\hline Tổng & 150 & 100 \\
\hline \multicolumn{3}{|l|}{ Mối quan hê quen biết với cán bô nhà nước } \\
\hline Nhà quản lý DN có quen biết với CBNN & 60 & 33,09 \\
\hline Nhà quản lý DN không có quen biết với CBNN & 111 & 66,91 \\
\hline Tổng & 171 & 100 \\
\hline \multicolumn{3}{|l|}{ Mối quan hệ quen biết với tổ chức/cá nhân CCDV } \\
\hline Nhà quản lý $\mathrm{DN}$ có quen biết với tổ chức/cá nhân CCDV & 40 & 23,39 \\
\hline
\end{tabular}




\begin{tabular}{lcc}
\hline \multicolumn{1}{c}{ Chỉ tiêu } & Tần số & $\begin{array}{c}\text { Tỷ trọng } \\
(\mathbf{\%})\end{array}$ \\
\hline $\begin{array}{l}\text { Nhà quản lý DN không có quen biết với tổ chức/cá nhân } \\
\text { CCDV }\end{array}$ & 131 & 76,61 \\
\hline Tổng & $\mathbf{1 7 1}$ & $\mathbf{1 0 0}$ \\
\hline
\end{tabular}

Nguồn: Kết quả xử lý từ dữ liệu điều tra

\subsection{Các nhân tố ảnh hưởng quyết định thuê dịch vụ thụcc hiện thủ tục đăng ký doanh nghiệp}

Trước khi áp dụng phương pháp hồi quy, tác giả có kiểm định mối tương quan giữa các biến độc lập trong mô hình và kết quả cho thấy các biến có mức độ tương quan thấp nên vấn đề đa cộng tuyến không đáng kể. Kết quả ước lượng mô hình logit được trình bày ở Bảng 3 :

\section{Bảng 3}

Kết quả ước lượng mô hình hồi quy Logit

\begin{tabular}{lcc}
\hline \multicolumn{1}{c}{ Biến } & Hệ số ước lượng & Giá trị z \\
\hline Chi phí bằng tiền DN phải bỏ ra & $3,66^{* * *}$ & 3,73 \\
Thời gian DN phải bỏ ra & $0,23^{* *}$ & 2,14 \\
Các loại giấy tờ DN biết được khi thực hiện thủ tục & $-9,1^{* * *}$ & $-4,42$ \\
đăng ký & & 1,43 \\
Khoảng cách địa lý từ trụ sở của doanh nghiệp đến nơi & 0,30 & - \\
đăng ký thủ tục & & 2,42 \\
Qui mô DN & $0,0002^{* * * *}$ & - \\
& & - \\
Doanh nghiệp đăng ký sau năm 2015 & $2,54^{* * *}$ & - \\
& & 0,58 \\
Người quản lý DN có quen biết với CBNN & 0.56 & $-0,13$ \\
Người quản lý có quen biết với tổ chức/cá nhân CCDV & $-0,14$ & $-3,61$ \\
Tích số của chi phí bằng tiền và chi phí thời gian & $-0,11^{* * *}$ & $-2,03$ \\
Hằng số & $-3,74$ & 171 \\
\hline Số quan sát & & 0,7903 \\
$\chi^{2}$ & & 0,000 \\
Mức ý nghĩa của mô hình Pr > $\chi^{2}$
\end{tabular}

Ghi chú: ***: mức ý nghĩa $1 \% \quad$ **: mức ý nghĩa $5 \%$

Nguồn: Kết quả phân tích từ mẫu nghiên cứu gồm 171 doanh nghiệp năm 2018 
Theo kết quả trong Bảng 3 hầu hết các hệ số của các biến độc lập trong mô hình đều có ý nghĩa thống kê $5 \%$, ngoại trừ các biến: khoảng cách địa lý, người quản lý $\mathrm{DN}$ có quen biết với $\mathrm{CBNN}$, người quản lý $\mathrm{DN}$ có quen biết với tổ chức/cá nhân CCDV. Trong đó, tác động của các biến có ý nghĩa thống kê cụ thể như sau:

\section{Nhóm biến lọii ích}

Phí dịch vu DN phải bỏ ra: Hệ số của biến phí dịch vụ có ý nghĩa thống kê ở mức $1 \%$ và dương. Điều này cho thấy rằng xác suất thuê ngoài của doanh nghiệp đồng biến với chi phí bằng tiền doanh nghiệp phải bỏ ra để thực hiện đăng ký doanh nghiệp. Do đó, có thể nói chi phí bằng tiền doanh nghiệp phải bỏ ra đóng vai trò quan trọng trong việc doanh nghiệp quyết định thuê ngoài dịch vụ thực hiện thủ tục đăng ký doanh nghiệp.

Thời gian doanh nghiệp phải bỏ ra: Hệ số của biến thời gian doanh nghiệp phải bỏ ra có ý nghĩa thống kê ở mức $1 \%$ và dương, cho thấy thời gian mà doanh nghiệp ước tính sẽ tốn kém cho việc làm thủ tục tỷ lệ thuận với xác suất thuê ngoài dịch vụ của doanh nghiệp. Điều này được giải thích rằng hiện nay thời gian doanh nghiệp phải bỏ ra từ việc chuẩn bị hồ sơ, chờ đợi nộp hồ sơ và nhận kết quả là rất nhiều do đó, thời gian doanh nghiệp phải bỏ ra càng nhiều thì xu hướng doanh nghiệp sẽ quyết định thuê ngoài dịch vụ càng cao.

Tích số của phí dịch vu và chi phí thời gian: Hệ số của biến này có giá trị âm và có ý nghĩa thống kê ở mức $1 \%$. Điều này cho thấy khi doanh nghiệp càng bỏ ra nhiều tiền thì càng muốn ít mất nhiều thời gian và ngược lại càng mất ít tiền thì sẽ mất nhiều thời gian đi lại để làm thủ tục.

Như vậy, tuy rằng doanh nghiệp phải tốn kém một số tiền khi doanh nghiệp quyết định thuê ngoài dịch vụ thực hiện thủ tục nhưng lợi ích từ việc tiết kiệm thời gian để có thời gian tập trung vào những phần việc chính là phù hợp với tình hình thực tế. Nghiên cứu của Bhagat và cộng sự (2010); Assaf và cộng sự (2011); Hafeez và Andersen (2014) cũng cho thấy kết quả tương tự.

\section{Nhóm biến kiến thức của người quản lý doanh nghiệp}

Các loại giấy tờ DN biết được khi thực hiện thủ tục đăng ký: Biến các loại giấy tờ được tìm thấy có ảnh hưởng đến quyết định thuê dịch vụ của doanh nghiệp, phù hợp với kỳ vọng ban đầu của mô hình nghiên cứu. Qua đó ta thấy được rằng, nếu doanh nghiệp biết được thành phần các loại giấy tờ cần thiết khi thực hiện thủ tục đăng ký càng nhiều thì doanh nghiệp sẽ quyết định không thuê. Điều này hoàn toàn phù hợp với giả thuyết đề ra ban đầu và kết quả nghiên cứu của Argyres (1996). Vì trong thực tế khi doanh nghiệp có hiểu biết về thủ tục hành chính cụ thể là thành phần hồ sơ yêu cầu khi thực hiện thủ tục thì doanh nghiệp sẽ có xu hướng không thuê ngoài dịch vụ. Bởi lẽ, khi tự thực hiện doanh nghiệp sẽ được hướng dẫn, tư vấn cụ thể, rõ ràng để có kinh nghiệm cho lần sau. Ngoài ra, doanh nghiệp sẽ hiểu được quyền lợi và trách nhiệm của mình sau khi thành lập doanh nghiệp.

\section{Nhóm biến đặc điểm doanh nghiệp}

Qui mô doanh nghiệp đang hoạt động: Kết quả ước lượng cho thấy biến qui mô doanh nghiệp có mối quan hệ tỷ lệ nghịch với khả năng thuê dịch vụ của doanh nghiệp. Điều này có nghĩa là khi qui mô doanh nghiệp càng lớn doanh nghiệp sẽ quyết định không thuê dịch vụ bên ngoài thực hiện thủ tục, đây cũng là điều rất phù hợp với kỳ vọng ban đầu của mô hình vì khi doanh nghiệp càng có quy mô lớn thì doanh nghiệp sẽ có bộ phận tự thực hiện thủ tục thay vì 
thuê dịch vụ. Kết quả này cũng đã được chứng minh trong nghiên cứu của Hafeez và Andersen (2014).

Doanh nghiệp đăng ký sau năm 2015: Phù hợp với kỳ vọng ban đầu của mô hình đề xuất nghiên cứu, biến số doanh nghiệp đăng ký sau năm 2015 có mối quan hệ tỉ lệ nghịch với xác suất thuê ngoài dịch vụ. Điều này có nghĩa là do Luật doanh nghiệp năm 2014 bắt đầu có hiệu lực năm 2015 đã rút ngắn thời gian giải quyết thủ tục đăng ký doanh nghiệp từ 5 ngày làm việc xuống còn 3 ngày làm việc để doanh nghiệp không phải mất nhiều thời gian chờ đợi để có được Giấy chứng nhận đăng ký doanh nghiệp vì vậy doanh nghiệp sẽ tiết kiệm được nhiều thời gian để tập trung cho những phần việc cốt lõi. Ngoài việc rút ngắn thời gian giải quyết thì thành phần hồ sơ như mẫu đơn, tờ khai đã được đơn giản hóa dễ hiểu, thống nhất và rõ ràng hơn. Bên cạnh đó, để tạo điều kiện cho các doanh nghiệp trong quá trình thực hiện thủ tục thì cơ quan cung cấp dịch vụ đã niêm yết các thủ tục hành chính tại Bộ phận tiếp nhận và trả kết quả cũng như đăng tải công khai lên Cổng thông tin Đăng ký doanh nghiệp nhằm tạo điều kiện cho các doanh nghiệp dễ dàng tiếp cận và rút ngắn thời gian đi lại cũng như thời gian cán bộ phải hướng dẫn cho doanh nghiệp.

\section{Kết luận và hàm ý chính sách}

Nghiên cứu này được thực hiện nhằm phân tích sự ảnh hưởng của các yếu tố đến quyết định thuê ngoài dịch vụ thực hiện thủ tục đăng ký doanh nghiệp của các doanh nghiệp tại Thành phố Cần Thơ với cỡ mẫu nghiên cứu là 171 doanh nghiệp bằng phương pháp phỏng vấn trực tiếp thông qua bản câu hỏi soạn sẵn.

Kết quả phân tích hồi quy nhị phân cho thấy có 5 yếu tố có ảnh hưởng đến quyết định thuê dịch vụ đăng ký doanh nghiệp bao gồm: Phí dịch vụ doanh nghiệp phải bỏ ra, Thời gian doanh nghiệp phải bỏ ra, Các loại giấy tờ $\mathrm{DN}$ biết được khi thực hiện thủ tục đăng ký, Qui mô của DN đang hoạt động, Năm thành lập của DN.

Kết quả nghiên cứu cũng cho thấy tuy doanh nghiệp phải bỏ ra một số tiền nhiều hơn nếu phải tự thực hiện nhưng doanh nghiệp không phải mất nhiều thời gian trong việc chuẩn bị hồ sơ cũng như ngồi chờ đợi nộp hồ sơ và nhận kết quả. Bên cạnh đó, mặc dù hiện nay việc các doanh nghiệp được đăng ký qua mạng nhằm tiết kiệm thời gian cho doanh nghiệp không phải chờ đợi hoặc đi lại nhiều lần nhưng kết quả triển khai thực hiện chưa được hiệu quả nên trong thời gian tới Sở Kế hoạch và Đầu tư Thành phố Cần Thơ cần quan tâm đến hình thức đăng ký qua mạng để giúp doanh nghiệp hiểu rõ được lợi ích từ hình thức đăng ký kinh doanh này. Thêm vào đó, Sở Kế hoạch và Đầu tư cần có những cuộc tuyên truyền pháp luật về việc tìm hiểu thủ tục hành chính giúp cho doanh nghiệp nắm được việc đăng ký doanh nghiệp là đơn giản, nhanh chóng và đặc biệt là lợi ích của doanh nghiệp có được khi tự thực hiện.

\section{Tài liệu tham khảo}

Alfred, C., Sumari, G. A., \& Mori, G. (2013). Outsourcing in cooperatives in Tanzania: Assessing the contribution of outsourcing on organizational performance. European Journal of Business and Management, 5(15), 99-104.

Argyres, N. (1996). Evidence on the role of firm capabilities in vertical integration decisions. Strategic Management Journal, 17(2), 129-50. 
Assaf, S., Hassanain, M. A., Al-Hammad, A.-M., \& Al-Nehmi, A. (2011). Factors affecting outsourcing decisions of maintenance services in Saudi Arabian universities. Property Management, 29(2), 195-212.

Belcourt, M. (2006). Outsourcing the benefits and the risks. Human Resource Management Review, 16(2), 269-279.

Bhagat, P., Byramjee, F., \& Taiani, V. (2010). A framework of total value orientation for strategic outsourcing decisions. Competitiveness Review: An International Business Journal, 20(4), 305-21.

Blau, P. M. (1977). A macrosociological theory of social structure. American Journal of Sociology, 83(1), 26-54.

Bourdieu, P. (1986). The forms of capital. In J. Richardson (Ed.), Handbook of theory and research for the sociology of education (pp. 241-258). Westport, CT: Greenwood.

Burt, R. S., \& Celotto, N. (1992). The network structure of management roles in a large matrix firm. Evaluation and Program Planning, 15(3), 303-326.

Chính phủ. (2010). Nghị định số 43/2010/NĐ-CP về đăng ký doanh nghiệp [Decree No. 43/2010/ND-CP on enterprise registration]. Retrieved January 20, 2018, from https://thuvienphapluat.vn/van-ban/doanh-nghiep/Nghi-dinh-43-2010-ND-CP-dang-kydoanh-nghiep-104230.aspx

Çiçek, I., \& Özer, B. (2011). The effect of outsourcing human resource on organizational performance: The role of organizational culture. International Journal of Business and Management Studies, 3(2), 131-144.

Coase, R. H. (1937). The nature of the firm. Economica, 4(16), 386-405.

Coleman, J. S. (1988). Social capital in the creation of human capital. American Journal of Sociology, 94, S95-S120.

Cooper, A. C., Gimeno-Gascon, F. J., \& Woo, C. Y. (1994). Initial human and financial capital as predictors of new venture performance. Journal of Business Venturing, 9(5), 371-95.

Cullinan, C. P., \& Zheng, X. (2015). Outsourcing accounting information systems: Evidence from closed-end mutual fund families. International Journal of Accounting Information Systems, 17, 65-83.

Djavanshir, G. R. (2005). Surveying the risks and benefits of IT outsourcing. IT Professional, 7(6), 32-37.

Earl, M. J. (1996). The risks of outsourcing it. Sloan Management Review, 37, 26-32.

Espino-Rodríguez, T. F., \& Padrón-Robaina, V. (2006). A review of outsourcing from the resource based view of the firm. International Journal of Management Reviews, 8(1), 4970.

Gilley, K. M., \& Rasheed, A. (2000). Making more by doing less: An analysis of outsourcing and its effects on firm performance. Journal of Management, 26(4), 763-790.

Granovetter, M. (1983). The strength of weak ties: A network theory revisited. Sociological Theory, 1, 201-233. 
Hafeez, A., \& Andersen, O. (2014). Factors influencing accounting outsourcing practices among smes in Pakistan context: Transaction Cost Economics (TCE) and ResourceBased Views (RBV) prospective. International Journal of Business and Management, 9(7), 19-32.

Hamzah, N., Aman, A., Maelah, R., Auzair, S. M., \& Amiruddin, R. (2010). Outsourcing decision processes: A case study of a Malaysian firm. African Journal of Business Management, 4(15), 3307-3314.

Hood, C. (1997). Which contract state? Four perspectives on over- outsourcing for public services. Australian Journal of Public Administration, 56(3), 120-131.

Kamyabi, Y., \& Devi, S. (2011). An empirical investigation of accounting outsourcing in Iranian smes: Transaction cost economics and resource-based views. International Journal of Business and Management, 6(3), 81.

Ketler, K., \& Walstrom, J. (1993). The outsourcing decision. International Journal of Information Management, 13(6), 449-459.

Kremic, T., Tukel, O. I., \& Rom, W. O. (2006). Outsourcing decision support: A survey of benefits, risks, and decision factors. Supply Chain Management, 11(6), 467-482.

Nordhaug, O. (1993). Human capital in organizations: Competence, training, and learning. Oslo, Norway: Scandinavian University Press.

Nyaboke, P. G., Amemba, C. S., \& Osoro, A. (2013). Factors affecting performance of outsourcing practice in the public sector in Kenya. International Journal of Research in Management, 5(3), 101-115.

O'Brien, D. (1976). Markets and hierarchies: Analysis and antitrust implications. The Economic Journal, 86(343), 619-621.

Quốc Hội. (2014). Luật số 68/2014/QH13 - Luật Doanh Nghiệp [Law No. 68/2014 / QH13 Enterprise Law]. Retrieved May 10, 2018, from https://luatvietnam.vn/doanhnghiep/luat-doanh-nghiep-2014-91359-d1.html

Sani, A., Dezdar, S., \& Sulaiman, A. (2013). Outsourcing patterns among Malaysian hotels. International Journal of Business and Social Science, 4(9), 133-144.

Tabachnick, B. G., \& Fidell, L. S. (1996). Using multivariate statistics. New York, NY: HarperCollins.

Wasserman, S., \& Faust, K. (1994). Social network analysis: Methods and applications. Cambridge, UK: Cambridge University Press.

Watts, D. J., \& Strogatz, S. H. (1998). Collective dynamics of 'small-world'networks. Nature, 393(6684), 440-442.

Yang, D.-H., Kim, S., Nam, C., \& Min, J.-W. (2007). Developing a decision model for business process outsourcing. Computers \& Operations Research, 34(12), 3769-3778. 